\title{
Synthesis of nano crystalline spatulae of lead zirconate titanate $\left(\mathrm{PbZr}_{0.52} \mathrm{Ti}_{0.48} \mathrm{O}_{3}\right)$
}

\author{
S. S. Bhatt ${ }^{*}$, S. C. Chaudhry, Neeraj Sharma, Sonia Gupta
}

Department of Chemistry, Himachal Pradesh University, Shimla, India; ssbhatt2k@yahoo.com

Received 15 October 2009; revised 29 October 2009; accepted 2 November 2009.

\begin{abstract}
A simple and effective method for the synthesis of nano-crystalline PZT spatulae has been reported near MPB via a new Solution-Ignition Synthesis route and has been characterized by FT-IR, XRD, TG/DTG/DTA and SEM techniques. $X$-ray line broadening and Scherrer formula show crystallite size to be $20 \mathrm{~nm}$. Densities of nano-crystalline spatulae of PZT in pellet form made by using $2 \%$ PVA and without PVA have been found to be 5.35 and $7.51 \mathrm{gm} / \mathrm{cm}^{3}$ respectively compared to the theoretical value of 7.78 $\mathrm{gm} / \mathrm{cm}^{3}$. Dielectric constants of 83 and 227 of these spatulae with dielectric loss 0.118 and 0.0609 at $1 \mathrm{MHz}$ and a high resistivity value of $3.043 * 10^{7} \Omega \mathrm{cm}$ for PZT pellets made without PVA suggest these nano-crystalline PZT spatulae to be the potential candidates for high frequency applications.
\end{abstract}

Keywords: Nanostructures; Chemical Synthesis; Infrared Spectroscopy; X-ray Diffraction; Dielectric Properties

\section{INTRODUCTION}

In advanced ceramics technology, the production of good quality powders using different synthetic routes has always been an essential requirement to obtain materials with desired properties, purity and stoichiometry. It is because of an ever-increasing pace of development of various technological innovations to sustain competitive advantage, that various synthetic methods such as selfpropagating high temperature synthesis (SHS) [1], solgel [2], hydrothermal [3-6], solution combustion synthesis (SCS) [7] and wet grinding solid state thermal reaction (a combination of SHS and SCS methods) [8] have been reported in literature for the preparation of inorganic oxide materials. Metal oxide of composition $\mathrm{PbZr}_{0.52} \mathrm{Ti}_{0.48} \mathrm{O}_{3}$, synthesized by sintering process between $1200^{\circ} \mathrm{C}$ and $1300^{\circ} \mathrm{C}$ is known to be quite impor- tant for technological applications due to its ferroelectric and piezoelectric properties near morphotropic phase boundary (MPB) $[9,10]$. For multilayer components and thick film devices, it is desirable to bring down its sintering temperature, thereby reducing energy consumption and $\mathrm{PbO}$ evaporation.

In view of these interesting reports, we have therefore made an attempt to synthesize nano-crystalline spatulae of lead zirconate titanate, $\mathrm{PbZr}_{0.52} \mathrm{Ti}_{0.48} \mathrm{O}_{3}$, near morphotropic phase boundary (MPB) by a novel method, solution ignition synthesis (SIS). This method is better than other methods in a way that by igniting the solution drop-wise, the surface area is increased and heat produced during ignition is sufficient to rise the internal temperature per ignited drop, thereby reducing the overall high temperature sintering requirement for the ceramics.

\section{MATERIALS AND METHODS}

\subsection{Chemicals}

The starting materials used for the preparation of lead zirconate titanate powder i.e. lead acetate $\mathrm{Pb}\left(\mathrm{CH}_{3} \mathrm{COO}\right)_{2}$. $3 \mathrm{H}_{2} \mathrm{O}$, zirconyl nitrate $\mathrm{ZrO}\left(\mathrm{NO}_{3}\right)_{2} \mathrm{H}_{2} \mathrm{O}$ and titanium tetra isopropoxide $\mathrm{Ti}\left[\left(\mathrm{OPr}_{4}^{\mathrm{i}}\right]\right.$ were of $\mathrm{E}$ Merck and used as such without further purification.

\subsection{Preparation of 'As-Ignited Powder'}

A solution of lead acetate $\mathrm{Pb}\left(\mathrm{CH}_{3} \mathrm{COO}\right)_{2} .3 \mathrm{H}_{2} \mathrm{O}(5 \mathrm{gm}$, $0.0131 \mathrm{~mol})$ in acetic anhydride was added drop-wise to a mixture solution of $\mathrm{ZrO}\left(\mathrm{NO}_{3}\right)_{2} . \mathrm{H}_{2} \mathrm{O}$, (1.5848gm, $00685 \mathrm{~mol})$ and titanium tetra isopropoxide $\mathrm{Ti}\left(\mathrm{OPr}^{\mathrm{i}}\right)_{4}$ $(1.7984 \mathrm{gm}, 0.006326 \mathrm{~mol})$ dissolved in the same solvent, with continuous stirring and a temperature of $60^{\circ} \mathrm{C}$ during the course of addition was maintained. The resulting clear mixture solution was then ignited by dropwise addition over aperiod of 4-5 hours into preheated silica crucible kept at $200^{\circ} \mathrm{C}$. Yellow colored solid mass formed during the course of addition was scratched from the walls of silica crucible after cooling it to room temperature. It was finally grinded to a fine powder and labeled as "as-ignited powder". The post annealing of the 
"as-ignited powder" was done in an electric furnace at $600^{\circ} \mathrm{C}$ and $700^{\circ} \mathrm{C}$ for four hours in each case.

\subsection{Instrumentation}

FTIR spectra were scanned in $\mathrm{KBr}$ pellets using single grating Nicolet 5700 series FTIR spectrophotometer in the range of $4000-200 \mathrm{~cm}^{-1}$. Thermal analysis curves (TGA/DTG/DTA) of the synthesized powders were recorded on a double pan SHIMADZU DTG-60H (simultaneous TG/DTA module) thermal analyzer. The thermocouple used was $\mathrm{Pt} / \mathrm{Pt}-\mathrm{Rh}(10 \%)$ with a temperature range from ambient to $1300^{\circ} \mathrm{C}$. The thermal investigations were carried out by heating the sample in a $\mathrm{Pt}$ crucible in nitrogen atmosphere and using $\alpha-\mathrm{Al}_{2} \mathrm{O}_{3}$ as reference. A heating rate of $20^{\circ} \mathrm{C} \mathrm{min}^{-1}$ was employed. The instrument calibration was checked periodically with a sample of $\mathrm{CuSO}_{4} \cdot 5 \mathrm{H}_{2} \mathrm{O}$. Powder X-Ray Diffraction patterns were recorded on PANalytical XPERT-PRO diffractometer system using a typical wavelength of $1.54060 \mathrm{~A}^{\circ}$ (Cu-K $\alpha$ radiation). The diffraction angle $2 \theta$ was varied from $10-70^{\circ}$. The morphology, exact size and shape of the lead zirconate titanate (PZT) particles were determined by recording FESEM of PZT powder annealed at $700^{\circ} \mathrm{C}$ on Hitachi S-4700 model.

For electrical measurements, two types of pellets, one by using $2 \%$ PVA as binder and other without PVA, were made from nano-crystalline PZT spatulae annealed at $700^{\circ} \mathrm{C}$. Pelletization was done by applying 15 tons of pressure on nano PZT powder put into a circular dye, from a hydraulic press for 5 minutes and then sintered at $700^{\circ} \mathrm{C}$. Both the sides of the sintered pellets were cleaned, smoothened with a very fine sand paper and electroded by applying silver paste. Current Voltage (I-V) measurements were made by using two probe method on Kaithley Source Meter (Model 2611), while dielectric studies were done by measuring capacitance of the sample with metal-insulator-metal (MIM), Agilent 4285A, $75 \mathrm{KHz}$ to $3 \mathrm{MHz}$ precision LCR meter.

\section{RESULTS AND DISCUSSION}

The synthesis of nano-crystalline PZT powder of composition $\mathrm{Pb}\left(\mathrm{Zr}_{0.52} \mathrm{Ti}_{0.48}\right) \mathrm{O}_{3}$ near MPB by Solution-Ignition Synthesis has been shown in Figure 1.

\subsection{FTIR Studies}

A perusal of the FTIR spectra of as-ignited PZT powder (Figure 2a) shows no absorption bands at $2912 \mathrm{~cm}^{-1}$, $1652 \mathrm{~cm}^{-1}$ and $1560 \mathrm{~cm}^{-1}$ attributed to $v_{\mathrm{C}-\mathrm{H}}$ and $v_{\mathrm{C}=\mathrm{O}}$ modes of acetate group indicating complete ignition of organic material used for the synthesis of samples. The absorption bands occurring at $1428 \mathrm{~cm}^{-1}$ and $1110 \mathrm{~cm}^{-1}$, may be ascribed to $v_{\mathrm{C}-\mathrm{O}}$ modes of the trapped atmospheric carbon dioxide in the PZT material [11]. Interestingly, the intensity of these two bands decreases signifi- cantly when annealed at $600^{\circ} \mathrm{C}$ (Figure 2b) and disappears completely at $700^{\circ} \mathrm{C}$ (Figure 2c). Another distinct absorption band observed at $563 \mathrm{~cm}^{-1}$ has been assigned to $v_{\mathrm{M}-\mathrm{O}}$ mode which is characteristic of the formation of $\mathrm{ABO}_{3}$ type of perovskite structure of PZT powder [12]. The effect of annealing at $600^{\circ} \mathrm{C}$ and $700^{\circ} \mathrm{C}$ on the characteristic bands is apparent from the shift of $v_{\mathrm{M}-\mathrm{O}}$ band from $563 \mathrm{~cm}^{-1}$ to higher wave numbers, $590 \mathrm{~cm}^{-1}$ and $592 \mathrm{~cm}^{-1}$ respectively, presumably due to increased number of $\mathrm{M}-\mathrm{O}$ bonds in the perovskite phase of PZT material. In addition, the band at $592 \mathrm{~cm}^{-1}$ in the sample annealed at $700^{\circ} \mathrm{C}$ has been found to be more intense than the band at $590 \mathrm{~cm}^{-1}$ annealed at $600^{\circ} \mathrm{C}$, confirming thereby the formation of more of perovskite phase at higher temperature.

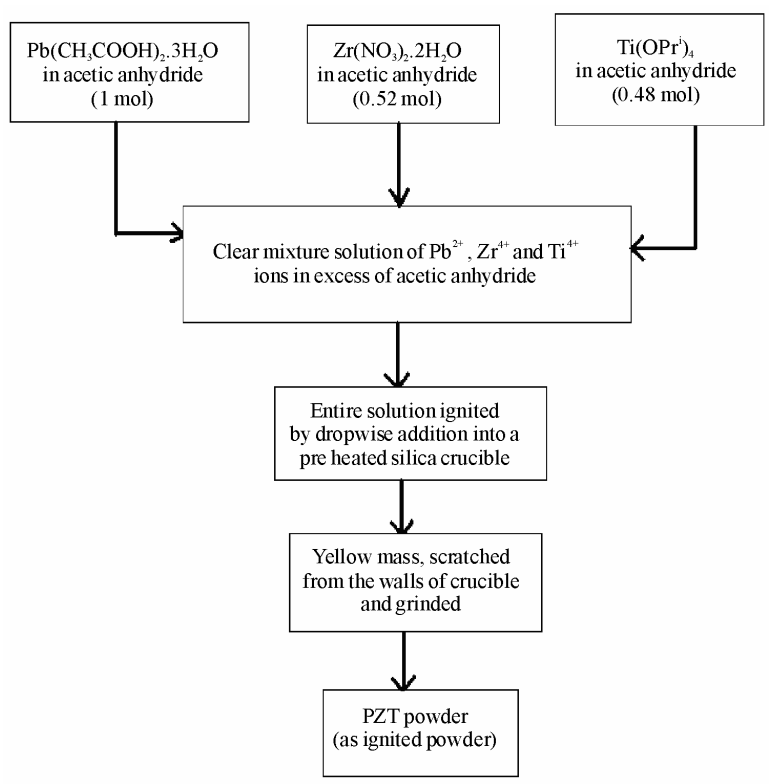

Figure 1. Scheme for the preparation of lead zirconate titanate powder by solution-ignition synthesis (SIS).

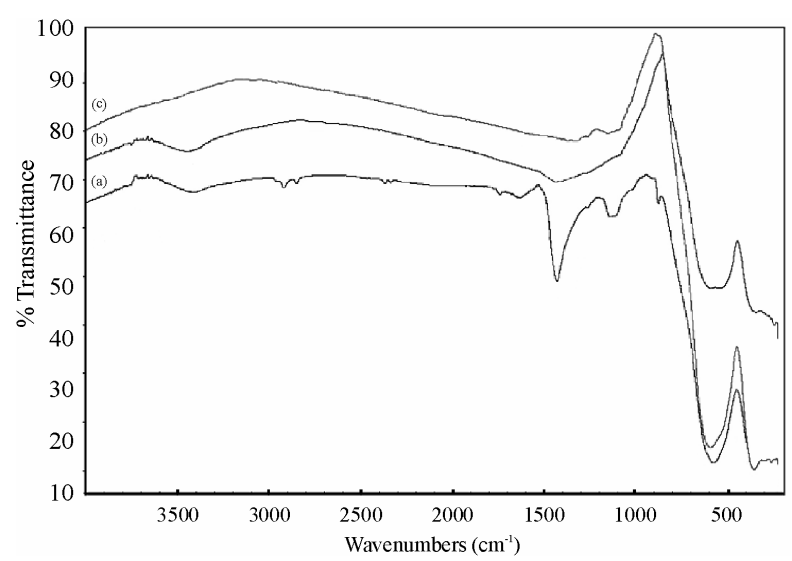

Figure 2. FTIR spectra of a) as-ignited PZT powder; b) powder annealed at $600^{\circ} \mathrm{C}$; c) powder annealed at $700^{\circ} \mathrm{C}$. 


\subsection{Thermal Analysis}

Thermo analytical curves (TG/DTG/DTA) for as-ignited PZT powder (Figure 3 blue in color) show only one step decomposition in the range $275.93^{\circ} \mathrm{C}$ to $331.77^{\circ} \mathrm{C}$ with a weight loss of only $1.005 \%$ as is also substantiated by only one peak in DTG at $311.52^{\circ} \mathrm{C}$ and an endothermic peak at $307.51^{\circ} \mathrm{C}$ in DTA curve indicated the escape of carbon dioxide gas trapped in as-ignited PZT powder. The TG/DTA curves (Figure 3 red in color) of as-ignited powder annealed at $600^{\circ} \mathrm{C}$, however, has shown neither any weight loss in TG nor any peak in DTA curve indicating the complete removal of carbon dioxide gas trapped in the lattice of nano-crystalline PZT powder.

\subsection{XRD Studies}

Powder XRD pattern of as-ignited PZT powder (Figure 4a) shows broad and an ordered arrangement of peaks, indicating the formation of nano-crystalline lead zirconate titanate, presumably resulting from the internal heat produced during drop-wise ignition of the reaction mixture solution. Further, the pyrochlore phase which was present initially at $28.5^{\circ} 2 \theta$ with relative intensity of $100 \%$ (657 counts) in as-ignited PZT powder (Figure 4a) gets significantly reduced at $600^{\circ} \mathrm{C}$ and completely transformed into perovskite phase at $31.0538^{\circ} 2 \theta$ value after annealing at $700^{\circ} \mathrm{C}$ (Figures $4 \mathbf{b}$ and $4 \mathbf{c}$ ). Apparently, therefore, the results of the PXRD patterns of as-ignited PZT powder coupled with FTIR and thermo analytical curves suggest that the solution ignition synthesis (SIS) is a novel method of synthesis of nanocrystalline PZT spatulae.

Indexing of the XRD patterns of nano-crystalline PZT powder annealed at $700^{\circ} \mathrm{C}$ (Figure 4c) has been done by matching them with the patterns of known PZT powder of composition $\mathrm{Pb}\left(\mathrm{Zr}_{0.52} \mathrm{Ti}_{.48}\right) \mathrm{O}_{3}[13,14]$. Lattice pa-

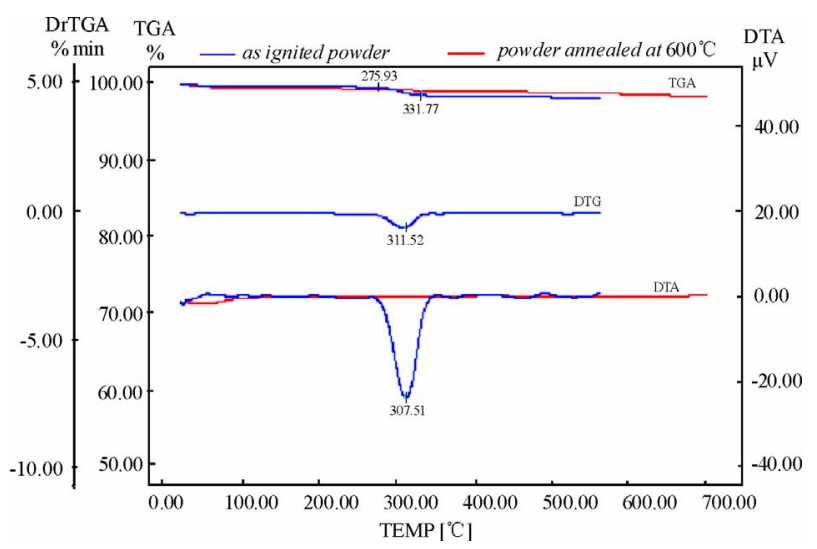

Figure 3. Thermal analysis (TGA/DTA/DTG) curves of as-ignited PZT powder (red) and PZT powder annealed at $600^{\circ} \mathrm{C}$ (blue).
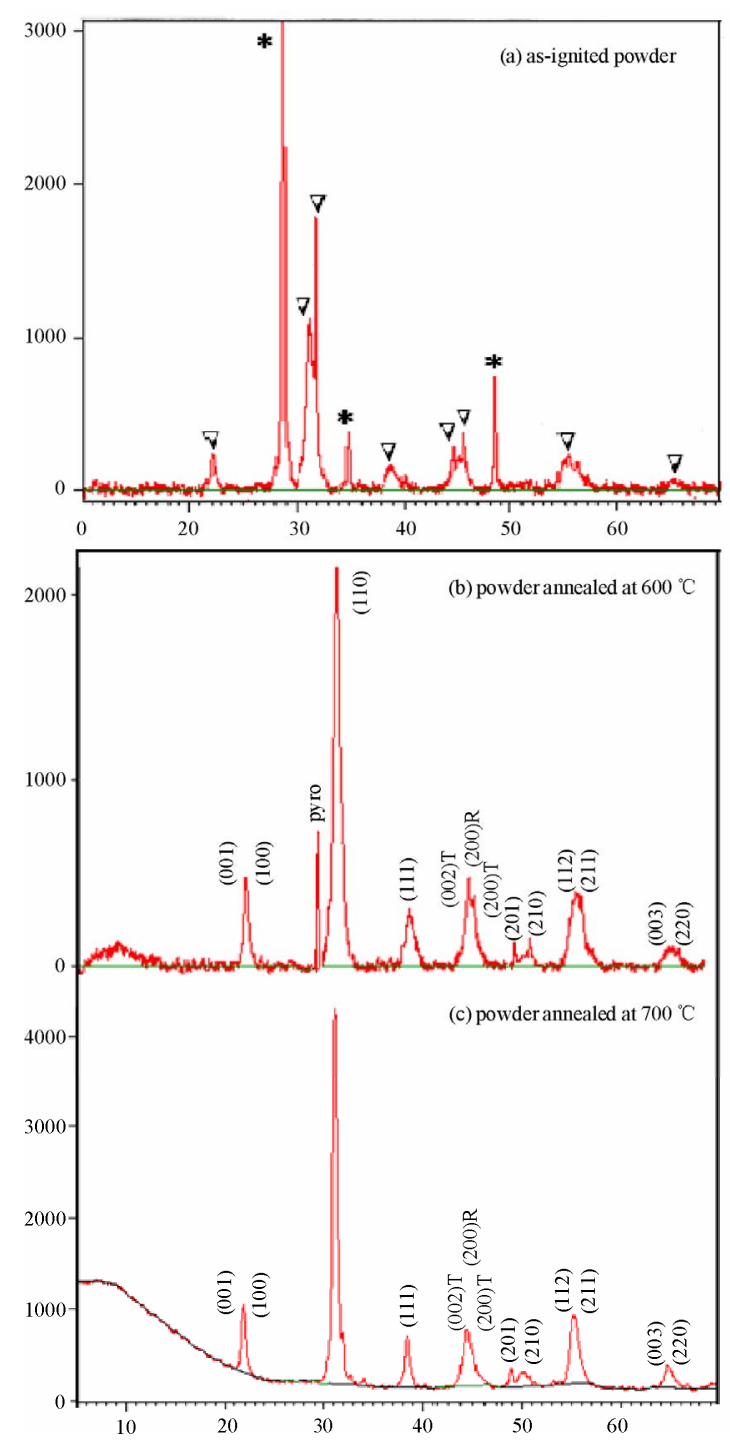

Figure 4. Powder X-ray diffraction patterns of: a) as-ignited PZT Powder; b) PZT powder annealed at $600^{\circ} \mathrm{C}$; and $\left.\mathrm{c}\right)$ at $700^{\circ} \mathrm{C}(\nabla$-Perovskite phase and $*-P y$ rochlore phase).

rameters of the sample annealed at $700^{\circ} \mathrm{C}\left(\mathrm{c}=4.32159 \mathrm{~A}^{\circ}\right.$ and $\left.\mathrm{a}=\mathrm{b}=4.06907 \mathrm{~A}^{\circ}\right)$ obtained from $(001)$ and (100) reflections at $20.5522^{\circ}$ and $21.8429^{\circ} 2 \theta$ values respectively in XRD pattern with slight lattice distortion (c/a) values to be 1.0620 have been found to be very close to that of 1.066 of pure tetragonal phase [15]. Further, the sharpness of the diffraction peaks in the XRD pattern (Figure 4c) suggests better homogeneity and crystallinity of the nano PZT spatulae. It is pertinent to mention here that with the increase in annealing temperature of as-ignited powder from $600^{\circ} \mathrm{C}$ and finally to $700^{\circ} \mathrm{C}$, a substantial increase in the intensity (counts) of the perovskite (110) orientation has been observed thereby confirming the enhanced crystallinity. 
The relative amounts of perovskite and pyrochlore phases (Table 1) have been determined from the relative intensity of XRD peaks by using following equation [16]:

$$
\% \text { perovskite phase }=\frac{I_{(110)}}{I_{(110)}+I_{(\text {pyro })}}
$$

where $\mathrm{I}_{(110)}$-relative intensity of the peak due to (110) orientation and $\mathrm{I}_{(\mathrm{pyro})}$-relative intensity of pyrochlore phase. A perusal of the results in Table 1 indicates that amount of pyrochlore phase decreases while the perovskite phase increases with the increase in annealing temperature.

Apart from the tetragonal phase depicted from the XRD pattern of the PZT powder annealed at $700^{\circ} \mathrm{C}$, the relative percentage of rhombohedral and tetragonal phases has been calculated from the triplets of the type (002)T, (200)R and (200) T appearing at $44^{\circ}-46^{\circ} 2 \theta$ range in the XRD pattern [17] using relation:

$$
\mathrm{P}_{\mathrm{R}}=\frac{I_{R(200)}}{I_{R(200)}+I_{T(200)}+I_{T(002)}}
$$

where $P_{R}$ represents rhombohedral phase, $I_{R(200)}$ is intensity of (200) reflection of rhombohedral phase, $\mathrm{I}_{\mathrm{T}}(200)$ and $\mathrm{I}_{\mathrm{T}(002)}$ is intensity of (200) and (002) reflections of tetragonal phase. The results show that percentage of rhombohedral and tetragonal phase in the present nanocrystalline PZT powder is $30 \%$ and $70 \%$ respectively indicating thereby that the chemical composition of synthesized nano-crystalline PZT powder lies near to Morphotropic Phase Boundary.

\subsection{Crystallite Size, Shape and Density}

\subsubsection{Size}

Broadening of the peaks observed in the XRD patterns (Figures 4a-4c) indicates particles in the nano range. Crystallite size of the nano-crystalline PZT powder an-
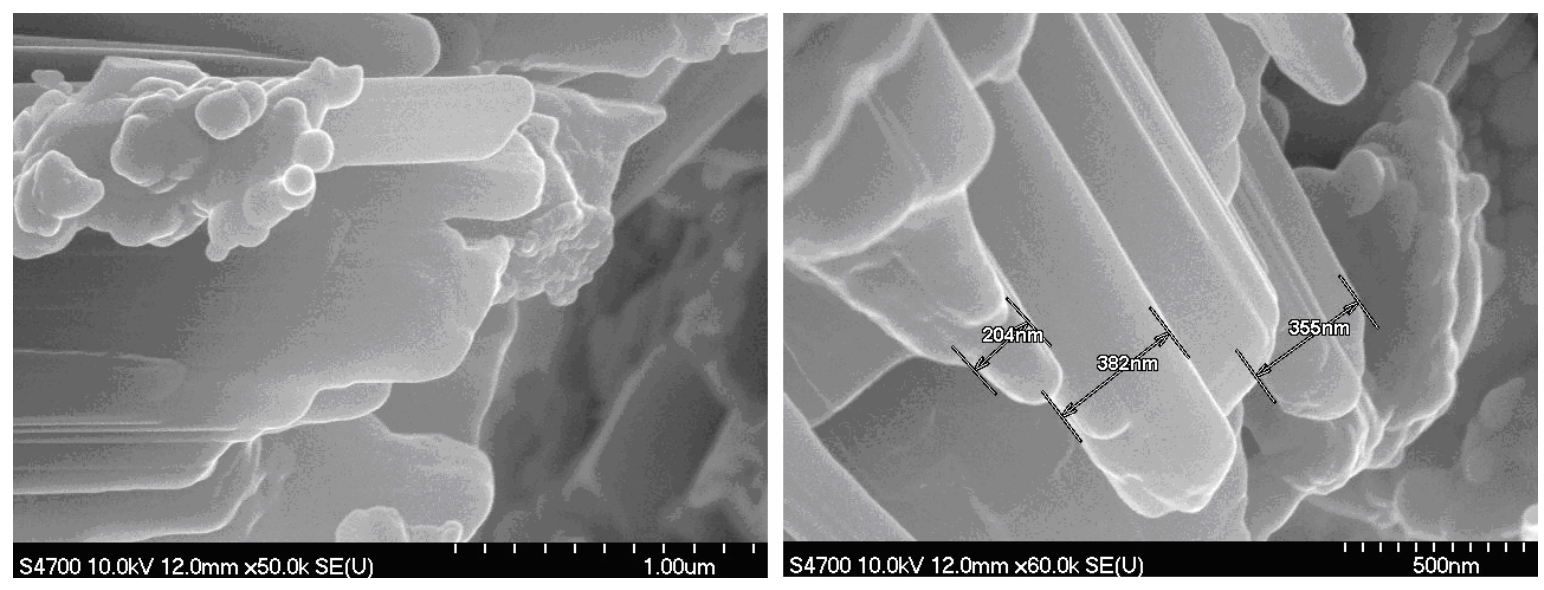

Table 1. \% phases in the nano-crystalline PZT powder samples.

\begin{tabular}{clcc}
\hline $\begin{array}{c}\text { S. } \\
\text { No. }\end{array}$ & \multicolumn{1}{c}{ Name of Sample } & $\begin{array}{c}\% \\
\text { Perovskite }\end{array}$ & $\begin{array}{c}\% \\
\text { Pyrochlore }\end{array}$ \\
\hline 1 & As-ignited powder & 36.10 & 63.89 \\
2 & $\begin{array}{l}\text { Powder annealed at } \\
600^{\circ} \mathrm{C}\end{array}$ & 71.81 & 28.18 \\
3 & $\begin{array}{l}\text { Powder annealed at } \\
700^{\circ} \mathrm{C}\end{array}$ & 97.43 & 2.57 \\
\hline
\end{tabular}

nealed at $600^{\circ} \mathrm{C}$ and $700^{\circ} \mathrm{C}$ has been calculated by using Scherrer Equation i.e.

$$
\text { Crysttalite size }=\frac{\mathrm{k} \lambda}{\beta \cos \theta}
$$

where $\boldsymbol{k}$ is the constant of proportionality (Scherrer constant) and depends on how the width line is determined and value of $\mathrm{k}$ is generally taken as 0.9 . $\lambda$ represents the wavelength of the $\mathrm{X}$ rays and has a value of $1.54060 \mathrm{~A}^{\circ}$,

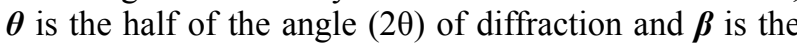
value of broadening of (110) line at Full Width Half Maximum (FWHM) of in radians and has been found to be $13.6 \mathrm{~nm}$ which increases to $21.4 \mathrm{~nm}$ respectively. Such an increase in the crystallite size with increase in annealing temperature finds support from earlier reports in literature $[18,19]$.

\subsubsection{Shape}

FESEM of the nano-crystalline PZT powder annealed at $700^{\circ} \mathrm{C}$ (Figure 5) shows a mixture of both spherical particles and stacks of nano spatulae of about $204 \mathrm{~nm}$ in width. The spherical nature of the crystallite has been attributed to the high pressure exerted by the evolution of gases such as $\mathrm{CO}_{2}, \mathrm{~N}_{2}, \mathrm{O}_{2}$, etc. during the course of ignition reaction [20] while the formation of stacks of nano spatulae may be attributed to the partial melting and subsequent solidification during dropwise ignition of the PZT powder in the preheated silica crucible.

Figure 5. FESEM of nano-crystalline PZT spatulae. 


\subsubsection{Densities and Porosity}

Densities of pellets of nano-crystalline PZT powder (one made with $2 \%$ PVA as a binder and other without PVA each of $15 \mathrm{~mm}$ in diameter and $1.3 \mathrm{~mm}$ thickness) measured by Archimedes Principle have been found to be 5.35 and $7.51 \mathrm{gm} / \mathrm{cm}^{3}$ respectively. These densities are $68.76 \%$ and $96.5 \%$ of the theoretical value $(7.78$ $\mathrm{gm} / \mathrm{cm}^{3}$ ). The percentage porosity of PZT pellets has been calculated from the relation:

$$
\% \text { porosity }=\left(1-\rho / \rho_{0}\right) \times 100
$$

where $\boldsymbol{\rho}$ and $\boldsymbol{\rho}_{\mathbf{0}}$ are the experimental and the theoretical densities of PZT $\left(7.78 \mathrm{gm} / \mathrm{cm}^{3}\right)$ and have been found to be $31.24 \%$ and $3.48 \%$.

\subsection{Electrical Properties of Lead Zirconate Titanate of Composition $\mathrm{Pb}\left(\mathrm{Zr}_{0.52} \mathrm{Ti}_{0.48}\right) \mathrm{O}_{3}$}

\subsubsection{C. Resistivity}

Resistivity has been obtained from current-voltage studies of the pellet prepared from nano-crystalline PZT powder annealed at $700^{\circ} \mathrm{C}$ by the two probe method using a Keithley Source meter (Model 2611). From a plot of Current vs Voltage (Figure 6) resistance ' $R$ ' has been calculated from the slope of the plot as, slope $(R)=I / V$ and the resistivity ' $\rho$ ' using the well known relation, $\rho$ (ohm meter $)=\frac{R A}{d}$ where $\boldsymbol{A}$ represents the area of the cross section and $\boldsymbol{d}$ is the thickness of the pellet.

A high resistivity value of $3.043 * 10^{7} \Omega \mathrm{cm}$ found in the present studies has been attributed to the stoichiometric composition, better crystal structures and improved microstructures obtained by this new solution ignition synthesis (SIS) technique. The higher value of resistivity is also of significant importance as it makes this nano-crystalline PZT spatulae suitable for high frequency application.

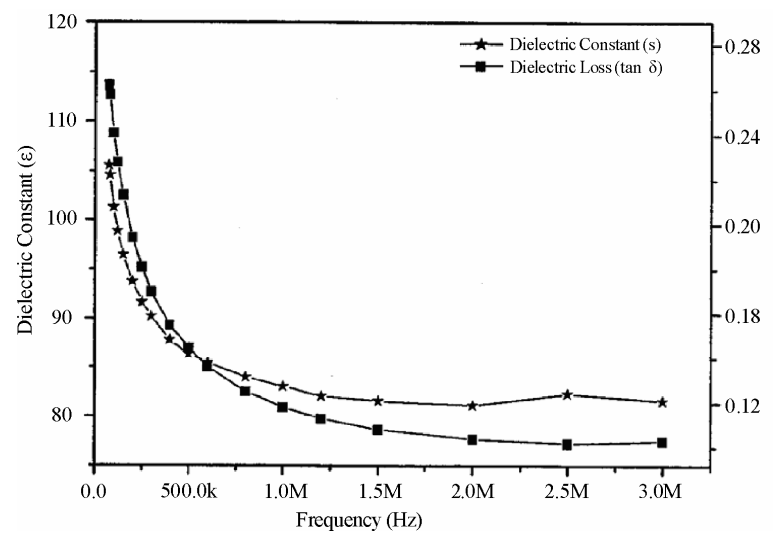

(a)

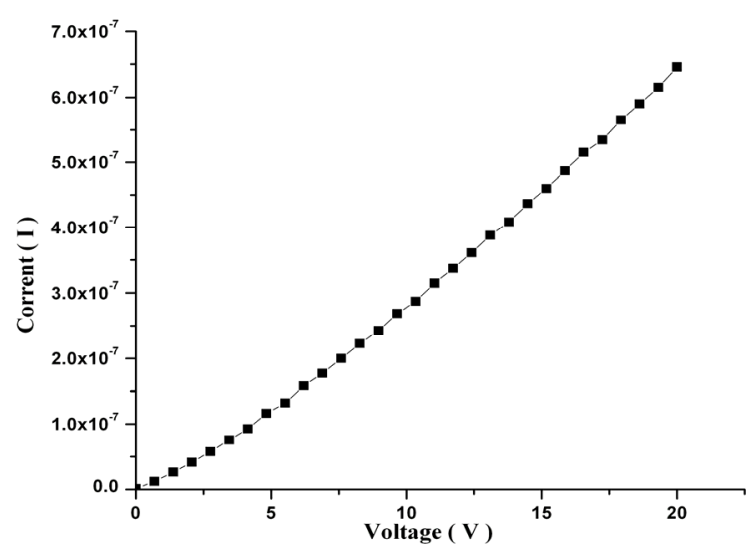

Figure 6. Current (I) vs Voltage (V) plot of nano-crystalline PZT pellet.

\subsubsection{Dielectric Studies}

The dielectric constant $(\varepsilon)$ and dielectric loss $(\tan \delta)$ of sintered pellets of nano-crystalline PZT spatulae (with $2 \%$ PVA and without PVA) as function of frequency at different temperatures have been studied and trends are shown as graphs in Figures $7 \mathbf{a}$ and $7 \mathbf{b}$. The values of 83 and 227 for dielectric constant and 0.118 and 0.0609 for dielectric loss have been found at a frequency of $1 \mathrm{MHz}$ which remains nearly same in the higher frequency range (up to $3 \mathrm{MHz}$ ). Further, a comparison of the values of both dielectric constant (227 and 249) and dielectric loss $(0.0609$ and 0.042$)$ at $298 \mathrm{~K}$ and $373 \mathrm{~K}$ respectively at constant frequency of $1 \mathrm{MHz}$ (Figure 8) shows an increase in dielectric constant with decrease in dielectric loss values. These observed low values of dielectric constants have been found to be in agreement with the fact that small grains attain low values of dielectric constant and can stabilize dielectric relaxation up to higher frequency region [21]. These studies also indicate that nanocrystalline spatulae of lead zirconate titanate, $\mathrm{Pb}$ $\left(\mathrm{Zr}_{0.52} \mathrm{Ti}_{0.48}\right) \mathrm{O}_{3}$ synthesized near MPB with almost same values of dielectric constant and dielectric loss over a large range of frequencies (up to $3 \mathrm{MHz}$ ) may find their role as successful and stable dielectrics in the field of electronics.

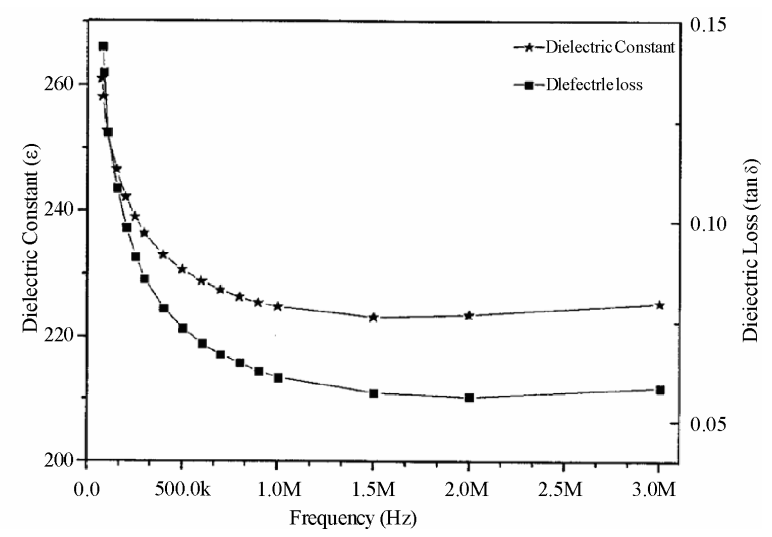

(b)

Figure 7. Variation of dielectric constant and dielectric loss with frequency at room temperature for: a) PZT pellet with 2\% PVA; and b) PZT pellet without PVA. 


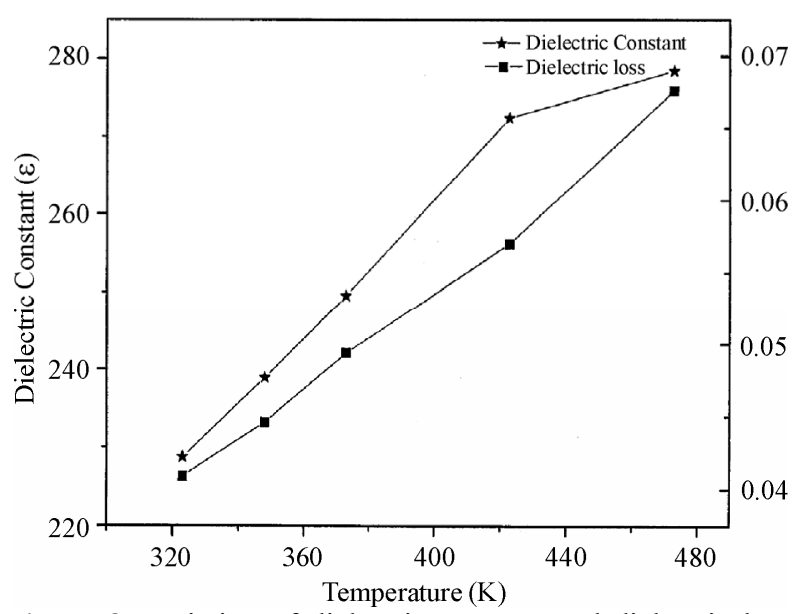

Figure 8. Variation of dielectric constant and dielectric loss with temperature at $1 \mathrm{MHz}$ frequency for PZT pellet without PVA.

\section{CONCLUSIONS}

The present work describes a simple, effective and novel synthetic strategy namely Solution Ignition Synthesis (SIS) route for the preparation of nano-crystalline PZT, which is advantageous over other commonly employed methods. The FTIR and XRD patterns of the nano crystalline PZT spatulae confirmed their perovskite structure near MPB. The dielectric constant and high values of resistivity also suggest that they may find their role as potential materials suitable for high frequency applications and as stable dielectrics.

\section{ACKNOWLEDGEMENTS}

The authors wish to acknowledge University Grants Commission, New Delhi and Department of Science and Technology, GOI for providing necessary instrumentation facilities and financial support in the form of SAP and FIST programs to the Department of Chemistry.

\section{REFERENCES}

[1] Merzhanov, A.G. (1990) Twenty years of search and findings in combustion and Plasma Synthesis of high temperature materials. Edited by Munir, Z.A. and Holt, J. B., New York VCH Publ. Inc., 1-35.

[2] Livage, J. (1994) The sol-gel route to advanced materials. Mater. Sc. Forum, 152 \& 153, 43-54.

[3] Cheng, H.M., Ma, J.M., Zhu, B. and Cui, Y.H. (1993) Reaction mechanisms in the formation of lead zirconate titanate solid solutions under hydrothermal conditions. $J$. Am. Ceram. Soc., 76(3), 625-629.

[4] Traianidis, M., Courtois, C., Leriche, A. and Thierry, B. (1999) Hydrothermal synthesis of lead zirconium titanate
(PZT) powders and their characteristics. J. Europ. Ceram. Soc., 12(19), 1023-1026.

[5] Kutty, T.R.N. and Balachandran, R. (1984) Direct precipitation of lead zirconate titanate by the hydrothermal method. Mater. Res. Bull., 19(11), 1479-1488.

[6] Lencka, M.M., Anderko, A. and Riman, R.E. (1995) Hydrothermal precipitation of lead zirconate titanate solid solutions: thermodynamic modeling and experimental synthesis. J. Am. Ceram. Soc., 78(10), 2609-2618.

[7] Mukasyan, A.S. and Dinka, P. (2007) Novel approach to solution-combustion synthesis of nano-materials. Int. J. Self Propagating High Temperature Synthesis, 16(1), 23-35.

[8] Vijaya, M.S., Senthilkumar, R., Sridevi, K. and Subramnia, A. (2005) Preparation and piezoelectric properties of lead zirconate titanate ceramics. Ferroelectrics, 325, 43-48.

[9] Jaffe, B., Roth, R.S. and Marzullo, S. (1954) Piezoelectric properties of lead zirconate lead titanate solid solution ceramics. J. Appl. Phys., 25, 809-810.

[10] Kakegawa, K., Mohri, J., Shirasaki, S. and Takahasi, K. (1982) Sluggish pansition between tetragonal and rhombohedral phases of $\mathrm{Pb}(\mathrm{Zr}, \mathrm{Ti}) \mathrm{O}_{3}$ prepared by application of electric field. J. Am. Ceram. Soc., 65(10), 515-519.

[11] Wang, Y. and Jorge, J. (2003) FTIR characterization of PZT nano fibers synthesized from metallo-organic compounds using electro spinning. Mat. Res. Soc. Symp. Proc., 736, D2.9.1-D2.9.6.

[12] Samuneva, B., Jambazov, D., Lepkova, D. and Dimitriev, Y. (1990) Sol-gel synthesis of $\mathrm{BaTiO}_{3}$ and $\mathrm{Ba}_{1-x-y} a_{y} \mathrm{Sr}_{x}$ $\left.\mathrm{Zr}_{\mathrm{y}} \mathrm{Ti}_{1-\mathrm{y}}\right) \mathrm{O}_{3}$ perovskite powders. Ceram. Int., 16, 355-360.

[13] Sen, A., Seal, A., Das, N., Mazumdar, R. and Maiti, H.S. (2005) Technological challenges of making PZT based piezoelectric wafers. Proc. Int. Conf. Smart Mater. Str. Sys., SC41-SC48.

[14] Kakegawa, K., Mohri, J., Takahashi, T., Yamamura, H. and Shirasaki, S. (1977) Compositional fluctuation and properties of $\mathrm{Pb}(\mathrm{Zr}, \mathrm{Ti}) \mathrm{O}_{3}$. Powder Diffraction File PDF2 Database Sets 1-45, International Centre for Diffraction Data (ICDD), 24, 769-772.

[15] Chu, S.Y. and Chen, C.H. (2001) Effect of calcium on the piezoelectric and dielectric properties of Sm-modified $\mathrm{PbTiO}_{3}$ ceramics. Sensors and Actuators, 89 (3), 210-214.

[16] Lakeman, C.D.E. and Payne, D.A. (1992) Processing effects in the sol gel preparation of PZT dried gels, powders and ferroelectric thin layers. J. Am Ceram. Soc., 75, 3091.

[17] Mishra, S.K., Pandey, D. and Singh, A.P. (1996) Effect of phase coexistence at morphotropic phase boundary on the properties of $\mathrm{Pb}\left(\mathrm{Zr}_{x} \mathrm{Ti}_{1-x}\right) \mathrm{O}_{3}$ ceramics. Appl. Phys. Lett., 69, 1707-1709.

[18] Thamjaree, W., Nhuapeng, W. and Tunkasiri, T. (2004) Analysis of X-ray diffraction line profiles of lead zirconate titanate using fourier method. Ferroelectric Letter, 31, 79-85.

[19] Verma, K.C., Kotnala, R.K., Mathpal, M.C., Thakur, N., Gautam, Prikshit and Negi, N.S. (2009) Dielectric properties of nano-crystalline $\mathrm{Pb}_{0.8} \mathrm{Zr}_{0.2} \mathrm{TiO}_{3}$ thin films at different annealing temperature. Materials Chemistry and Physics, 114, 576.

[20] Nersisyan, H.H., Lee, J.H. and Won, C.W. (2005) SHS of ceramic powders in the fusion salts of alkali metal. $J$. Ceram. Process. Res., 6(1), 41-47. 